\title{
CUANDO LA INTIMIDAD SE INTERPRETA COMO TRAICIÓN. MENORCA 1781
}

\author{
MARÍA LUISA ÁLVAREZ Y CAÑAS \\ Universidad de Alicante
}

Fecha de recepción: noviembre 2011

Fecha de aceptación: febrero 2012

El 19 de agosto de 1781 la escuadra del teniente general duque de Crillón apoyada por un contingente de tropas francesas desembarcó en Menorca para la conquista de su territorio. A partir de entonces comenzó a materializarse la vieja ambición de recuperar uno de los dos enclaves perdidos por la Corona española tras finalizar la Guerra de Sucesión. Debido a su privilegiada situación geopolítica en el Mediterráneo, la soberanía de la isla suponía obtener el control y procurar la defensa del tráfico naval, hasta entonces acosado por los corsarios mahoneses que actuaban bajo bandera inglesa, además de anular su primordial condición de enlace político y económico con Gibraltar, en una operación considerada de indiscutible trascendencia internacional.

Su reconquista no sólo significó el cambio de nacionalidad y jurisdicción administrativa de los menorquines, que hasta esa fecha habían conservado sus derechos tradicionales y su gobierno municipal, sino que afectó a distintos colectivos protegidos durante la dominación inglesa, y alteró la vida cotidiana de todos sus habitantes hasta límites insospechados. Así, frente a la tolerancia en la que habían convivido los súbditos británicos y la población autóctona, junto a una importante comunidad de comerciantes extranjeros, entre los que destacaban los griegos y los judíos, la presencia española impuso la normativa política recogida en el Tratado de Utrech ${ }^{1}$, en defensa de la religión católica sobre el resto de confesiones ${ }^{2}$.

En consecuencia, la isla fue sometida al estado de excepción, de manera que todos los asuntos gubernativos en cualquiera de sus dependencias y que trascendían a la mera conquista militar fueron asumidos por la Secretaría del Despacho de Guerra. El duque

1. A.G.S., Guerra Moderna, Leg. 3.768: Bando del duque de Crillón, 27 de agosto de 1781.

2. LaLinde ABADÍA, Jesús: Iniciación Histórica al Derecho Español, Barcelona, 1978, p. 696. 
de Crillón obtuvo el poder político-militar en Menorca $^{3}$, y desde esa responsabilidad de mando atendió a las necesidades prioritarias de defensa y orden público ${ }^{4}$ : por un lado, con el objetivo de lograr la rendición de los ingleses y, por otro, para establecer las instituciones y el método de gobierno de la administración española sobre los menorquines.

\section{SOSPECHAS DE TRAICIÓN ENTRE LOS HABITANTES DE MENORCA}

Para comenzar a tomar las riendas de este territorio las autoridades españolas se instalaron en la ciudad de Mahón, la capital elegida en el año 1722 por los ocupantes, ante la urgencia de asediar a la guarnición británica que, junto a parte de sus compatriotas civiles, se había atrincherado en la fortaleza de San Felipe.

A pesar de haber contado desde el momento de la conquista con el apoyo de la población civil, la imposición de la nueva soberanía supuso el aumento de las precauciones sobre los posibles casos de traición de parte de los habitantes de la isla. La inseguridad provenía de la eventual existencia de mahoneses afectos al dominio británico, que podían estar implicados en presumibles sabotajes contra los intereses de la monarquía española. Era fácilmente perceptible el grado de entendimiento de las distintas nacionalidades presentes en Menorca, sustentado en los casi setenta años de hegemonía inglesa, y reforzado en las habituales y frecuentes relaciones comerciales entabladas entre las mismas ${ }^{5}$.

Las sospechas de infidencia y espionaje, acrecentadas por la crítica situación de asedio contra los ingleses, alteraron en muchos aspectos la vida cotidiana de los mahoneses. Así fueron extendiéndose los arrestos y la imputación de delitos bajo la común denominación de traiciones en el intento de neutralizar los apoyos civiles a la causa de la guarnición británica, aún invicta y que se hallaba refugiada en el castillo de San Felipe. Además, en estas circunstancias fueron periódicas y habituales las detenciones sobre marineros cuyas embarcaciones se aproximaban a la isla sin conocer aún la nueva situación política, o relativas al arbitrio sobre pertenencias comerciales de ingleses y otros extranjeros, o sobre la naturaleza de individuos sin identificar.

El responsable de llevar a cabo las averiguaciones y la subsiguiente represión del delito de traición fue Juan Bautista de San Martín y Navaz. La transcendencia política de este personaje se revela en el relato de sus propias impresiones acerca de la gestión que le fue encomendada en Menorca ${ }^{6}$. San Martín y Navaz, del Consejo de

3. Sobre los orígenes y la trayectoria de este teniente general, Vid., TERRÓN PONCE, José Luis: La toma de Menorca, 1781-1782: en los escritos autobiográficos y epistolarios del Duque de Crillón, Mahón, 1998, pp. $162-170$.

4. A.G.S., Guerra Moderna, Leg. 1369: «Resolución para que las cosas de Menorca se gobiernen por las Secretarias de Despacho respectivas».

5. PIÑA HOMS, Román: La reincorporación de Menorca a la Corona Española 1781-1798 (Medidas de gobierno y Administración), Palma de Mallorca, 1983, pp. 26-28.

6. A.G.S., Guerra Moderna, Leg. 1369: «Memorial de D. Juan Bautista de San Martín y Navaz, 15 de febrero de 1782». 
Su Majestad, alcalde honorario de su Real Casa y Corte, y auditor general del ejército llegó a la isla en compañía del duque de Crillón para la conquista de Menorca. Su encargo en la isla para formar un reglamento de gobierno, «aunque sea para un Pueblo, el más infeliz», lo calificaba de «peliagudo», pues confesaba que el trabajo que debía desempeñar era superior a las fuerzas de un hombre solo. Su misión requería especial pericia en el ejercicio de autoridad y diplomacia, sobre todo porque Menorca era un territorio recién recuperado y aún parcialmente ocupado, circunstancias que exigían resolver cuantiosos y diferentes asuntos de la administración militar, política, económica y social con la destreza de no perjudicar al rey, y con la prudencia de no enaltecer los ánimos de los vasallos?

En principio pensaba que su comisión se ceñiría a tramitar todas las cuestiones de índole militar generadas en esas críticas fechas; sin embargo, los problemas que tuvo que afrontar desde el primer día fueron muy numerosos y graves, de forma que se sintió pronto desbordado. Por un lado, se trataba de poner en orden una isla sometida $\mathrm{y}$, por otro, los cometidos de los cinco jueces que la gobernaban hasta entonces, un asesor civil, uno criminal, uno del patrimonio, y dos jueces del almirantazgo (uno para las presas, y otro para el comercio y las cosas de la mar), quedaron suspensos con la llegada del ejército español, y todas sus atribuciones comprendidas bajo la jurisdicción de San Martín y Navaz.

La composición de la población era muy compleja pues además de los menorquines, se añadían los enemigos ingleses civiles y militares, más los griegos, los judíos y gentes de otras nacionalidades. Este panorama exigía tomar severas precauciones respecto a los mismos y a los que podían servirles de espías o confidentes, de forma que los sospechosos podían ser innumerables. En este sentido, presentaba los expedientes que en los primeros días se generaron a raíz de esas especiales circunstancias políticas.

El volumen de trabajo fue tan intenso que en ocasiones, como las de interrogar a acusados y testigos, no se vio interrumpido por las preceptivas horas de sueño, de forma que no se concluía el proceso hasta terminar las pesquisas necesarias para dictaminar sobre los presuntos delitos.

Incluso, pasada la inicial reorganización, San Martín y Navaz se hizo cargo del resto de asesorías con tal eficiencia que el duque de Crillón no formalizó los nombramientos precisos para su sustitución. Las disposiciones respecto a las circunstancias y el futuro de los extranjeros tras la conquista las entendía San Martín y Navaz como una «revolución», pues en definitiva llegaron a tramitarse en su Tribunal más de 250 expedientes a tal efecto, sin contar los numerosos juicios verbales celebrados en los primeros días que aligeraron la cifra anterior. Como prueba de la satisfacción de su

7. Para conocer las arduas tareas que se debían acometer con el fin de recuperar el control de la isla e implantar un nuevo gobierno Vid. IRLES VICENTE, $M^{\text {a }}$ del Carmen: «La vuelta de Menorca a manos de su Majestad Católica: la recuperación de Menorca en 1782 y la Nueva Planta militar», en BERNABÉ, D. y Alberola, A. (eds.): Magistro et Amico. Diez estudios en Homenaje al Profesor Enrique Giménez López, Alicante, 2012, pp. 175-198. Agradezco la atención de la autora por adelantarme la primicia de esta investigación así como sus inestimables orientaciones en el presente trabajo. 
ejercicio aseguraba que no recibió ninguna queja ni apelación a sus dictámenes. Es decir, a pesar de la instrucción de tal cantidad de pleitos había conseguido su despacho con profesionalidad y sin ocasionar consecuencias adversas entre la población.

\section{LAS INCONVENIENTES RELACIONES DE LAS MUJERES DE MAHÓN CON LOS INGLESES}

En dos expedientes cursados entre octubre y noviembre de 1781, aparecieron bajo sospecha un grupo de mujeres que hasta esos días habían mantenido estrechas relaciones con los ingleses, en condiciones distintas de intimidad, y pertenecientes a dos ámbitos sociales muy contrastados. El duque de Crillón, como comandante en jefe del Ejército de la expedición militar de Menorca y capitán general de la isla ordenó los trámites para que se procediera al arresto de las mismas, así como para la toma de declaraciones de testigos que pudieran aportar pruebas sobre su culpabilidad.

El primero de ellos concernía a la detención y traslado a la cárcel pública de diez mujeres de probada amistad y pública convivencia con los ingleses. Se les acusaba de traición a la Corona española bajo la sospecha de su continua comunicación con algunos de los integrantes de la guarnición británica que resistía en la fortaleza de San Felipe $^{8}$. En realidad, la mayoría pertenecía al mundo de la prostitución, actividad muy habitual en poblaciones con gran movimiento portuario, como ocurría en Menorca, donde además abundaba el género masculino con evidente desarraigo familiar, es decir, los militares británicos de distintas armas destinados a la guarnición de la isla, y los marineros dedicados al contrabando.

El segundo expediente afectaba al arresto de varios integrantes de una familia, en esta ocasión privados de su libertad en sus propios domicilios a causa de la correspondencia mantenida por dos de sus miembros con los enemigos. Se trataba de una mujer joven y su madre, la primera de ellas prometida en matrimonio a un oficial que, aunque nacido en Menorca, se encontraba al servicio del ejército británico9

A lo largo del siglo XVIII en la isla se había conservado el uso del menorquín como idioma habitual de sus residentes, en sus vertientes hablada y escrita ${ }^{10}$, y prueba de ello fue la necesidad de publicar los bandos en ese idioma y en castellano. Por lo tanto, fue necesario nombrar a un intérprete para la traducción al español de las respuestas contenidas en cada uno de los interrogatorios. La evidente anomalía en la ortografía de ciertos nombres obedecía a la literalidad de la transcripción, pues el traductor José Ximénez ${ }^{11}$ dictaba al escribano de Guerra la equivalencia de los sonidos

8. A.G.S., Secretaría de Despacho de Guerra, Leg. 7.312: «Expedición de Menorca. Traiciones», Expediente $\mathrm{n}^{\mathrm{o}} 48$.

9. A.G.S., Secretaría de Despacho de Guerra, Leg. 7.312: «Expedición de Menorca. Traiciones», Expediente $\mathrm{n}^{\mathrm{o}} 51$.

10. Lafuente Hernández, Eusebio: «Don Juan Silva. Conde de Cifuentes, Gobernador de Menorca», Revista de Menorca, Mahón, 1983, pp. 55-109.

11. Era notario público de la isla de Menorca, y practicó las funciones de traductor en varios de los expedientes substanciados por orden de San Martín y Navaz. 
en castellano de vocablos cuya escritura podía inducir a error, sobre todo de apellidos ingleses, de manera que a lo largo del expediente el mismo término aparecería escrito de distintas formas.

Por un auto fechado el 31 de octubre dieron comienzo las disposiciones que ordenaban los arrestos de las primeras sospechosas y la convocatoria de testigos para la averiguación de los hechos. El expediente generado a tal efecto reflejaba distintas noticias sobre un total de 35 mujeres residentes en Mahón, entre las cuales se encontraban las 10 detenidas, y además se añadían las declaraciones de tres testigos también mujeres. El relato aportado a partir de los interrogatorios a las presas y a las testigos reflejaba las relaciones de amistad, en unos casos, y de vecindad, en otros, que mantenían entre ellas. Pero existían otra serie de rasgos comunes que les asemejaban en su conjunto y les convertía en la muestra de un grupo de similar estatus social y económico.

- En primer lugar, la forma de identificarse:

La mayoría de ellas eran conocidas en su ambiente por sus apodos, o como se denominaba en menorquín por sus «malnoms». Estas eran las circunstancias de 5 de las arrestadas: Margarita Anglada, alias «Pegui»; Ana Anglés, alias «La Ferranda»; Juana María Corrones, alias «La Flamenca»; Margarita Gutiérrez, alias «Patrona»; Francisca Ortegas, alias «La Castellana»; también de una de las testigos: María Morla, alias «Pincha». Además, otras mujeres de su entorno eran apodadas como «Forenita», «Peu Descals», «La Roya», «La Della», «Cinc Sous», «La Monja»y «Negra». Dos de ellas heredaron el sobrenombre: Ana Anglés de su madre y Francisca Ortegas de su mentora e inductora en la profesión que ejercía. Asociados al mundo rural, a los gremios o a sectores marginales ${ }^{12}$, los apodos surgían como una necesidad de conocer a una persona y precisar su función social, en la que se solía destacar algo llamativo del aspecto externo, como «Peu Descals» o «Negra»; el carácter, «La Monja»; la actividad profesional, «Patrona» o «Cinc Sous» (Cinco Sueldos); el lugar de origen y residencia «La Della» (por Deià), o la etnia o religión a la que se pertenecía «Chueta» ${ }^{13}$. Al mismo tiempo, su utilización se extendió con el propósito de ofrecer señales de cercanía, vecindad y confianza. En ocasiones el alias era de origen castellano, mientras que en otras era menorquín, e incluso «anglo-menorquín» ${ }^{14}$, por la fusión de los idiomas hablados en esa isla, tal y como sucedía con María Morla, alias «Pincha», cuyo apodo probablemente derivaba del inglés pilchard, que alude a una clase de sardina en salazón llamada «pinxa», nombre castellanizado en la traducción del interrogatorio con la sustitución de la letra x por la ch. Otra alteración de la identidad se producía por la feminización de los apellidos: Eulalia y Catalina «Pola», en realidad se apellidaban Pol, fenómeno

12. Carrasco de la Fuente, Eva: «Aproximación a los conceptos del honor y la prostitución en la Barcelona del siglo XVIII», Las mujeres en el Antiguo Régimen, Barcelona, 1994, pp. 123-168.

13. MoreU-ReY, Enric: Renoms, motius i noms de casa, Barcelona, 1981, pp. 189-192.

14. En la actualidad aún se conservan en el idioma local más de 60 anglicismos. Melchor, Vicent de, y BRANCHADELL, Albert: El catalán: una lengua de Europa para compartir, Barcelona, 2002, pp. 112-113. 
que podía derivar y ser reforzado por el uso del laísmo observado también en los textos escritos siguiendo la pauta del traductor responsable.

- En segundo lugar, la vecindad:

La mayoría de las arrestadas vivía en el momento de su detención en la Explanada de Mahón o en las calles más proximas. Y en conjunto, también procedían del desalojo del mismo barrio llamado Arrabal Antiguo de San Felipe o Arrabal Viejo. Al resguardo del castillo de San Felipe, este barrio había sido edificado con el objetivo de proporcionar vivienda a los oficiales y los soldados que guarnecían la isla. Con el tiempo se formaron algunas familias y, con mayor frecuencia, todo tipo de relaciones de amistad, intimidad e incluso profesionales, que facilitaron la asimilación temporal del personal castrense. Dicho emplazamiento había sido derruido por los ingleses en $1777^{15}$, para evitar el peligro que en caso de un ataque a la fortaleza proporcionaría el resguardo de los enemigos entre las casas de ese recinto, tal y como había sucedido en la invasión francesa de $1756^{16}$. Así, la población debió ser acomodada en otros lugares de la isla, para lo cual además se acometió la construcción de Georgetown, un arrabal nuevo que también recibiría los nombres de Real Villa de San Carlos y Villacarlos, actualmente denominado Castells. Precisamente parte de las tropas acantonadas para la defensa de Menorca se encontraban alojadas en un cuartel establecido en la Explanada de Mahón, además de las apostadas en el nuevo emplazamiento de Georgetown y en el castillo de San Felipe ${ }^{17}$.

Como consecuencia de la escasez de casas y la precaria situación económica de estas mujeres, aquellas que carecían de familia o se separaron de la misma solían compartir casa o habitaciones en régimen de alquiler, generalmente en parejas de amigas, y también alojaban ocasionalmente a algún huésped. En ningún caso aparece una figura paterna o de cabeza de familia que dotara a sus vidas de una sensación de autoridad y de jerarquía e impusiera un orden. Sólo dos de las arrestadas habían conservado lazos de parentesco con quienes compartían sus domicilios: Clara Roig y Mariana Rechard

15. «Se ha hecho público de orden del comandante que el día 21 del mes que viene todo el arrabal de San Felipe ha de ser tirado abajo, lo que ha causado gran desolación y pena entre los pobres castellans». TATEISHI, Hirotaka: «Apuntes sobre el Diari de Mahó de Joan Roca i Vinent», Biblioteca Digital de Arqueología e Historia de Menorca, p. 97. <http://tufs.academia.edu/HirotakaTateishi/Papers/947816/ Apuntes_sobre_el_Diari_de_Maho_de_Joan_Roca_i_Vinent>; y RAMIS Y RAMIS, Juan y GELLA ITURRIAGA, José: Resumen topográfico e histórico de Menorca: manuscrito de 1787, Madrid, 1989, $\mathrm{p}$. 19.

16. El gobernador de la isla, Jorge Armstrong describía el arrabal de la siguiente manera: «Los alojamientos de los Oficiales, las casamatas de los Soldados, la Iglesia y algunos centenares de casas habitadas por los Españoles forman el arrabal de San Felipe». ARMSTRONG, Jorge: Historia Civil y Natural de la isla de Menorca, Madrid, 1781, pp. 37 y 65.

17. Vilardell SantacanA, Joan Enric: La Fundación de Georgetown 1771. Patrick Mackellar y el Urbanismo Militar Británico, Universidad Politécnica de Catalunya. Departament d'Urbanisme i Ordenacio del Territori (2005), Tesis Doctoral dirigida por José Luis Oyón Bañales, <http://hdl.handle. net/10803/6957> 
eran madre e hija, y aunque 15 días antes de su detención la segunda se había trasladado a la casa de Catalina Amorós, alias «La Negra», aquellas fueron circunstancialmente prendidas la noche del 31 de octubre bajo el mismo techo; Juana María Corrones, alias «Flamenca», tenía acogida a una niña de cuatro años (hija de un primo) que había quedado huérfana, mientras que su propia madre, a pesar de que compartía durante el día el mismo domicilio, se veía obligada a dormir en la casa inmediata de un vecino, a causa de que la propia era de dimensiones muy reducidas.

- En tercer lugar, la edad:

Dos de las detenidas habían llegado a los 40 años: Clara Roig, viuda de José Rechard, y Juana María Corrones «La Flamenca», viuda de Vicente Milort. El resto se encontraban entre los 20 y los 30 años de edad cumplidos, y sólo era menor Francisca Ortegas «La Castellana», que confesaba más de 16 años.

- En cuarto lugar, el estado civil:

Dicha circunstancia diversificaba en mayor grado al grupo de las mujeres aquí descritas. Sin embargo, a pesar de los diferentes estados civiles que se mostraban en este grupo sí era clara la evidencia común de hallarse solas, o sin una relación de estabilidad sentimental que conllevara la formación de una futura familia.

Además de las viudas arriba señaladas, se sumaba en igual situación Catalina Morro, una de las dos sospechosas a la que no se incluyó en la toma de declaraciones que formaron este expediente, junto a Catalina Pola, que tampoco aparecía en el interrogatorio. Aunque no constaba el nombre de su difunto marido, si precisaba que convivía en su casa con la testigo María Morla «Pincha», y que anteriormente había compartido su domicilio con la detenida Ana Anglés «La Ferranda».

En calidad de solteras se contabilizaban 6 mujeres: Margarita Anglada «Pegui», Francisca Ortegas «La Castellana», Mariana Rechard, Ana Anglés «La Ferranda», y las hermanas «Pola», Catalina y Eulalia. Respecto a las que declaraban encontrarse casadas, en realidad se hallaban en situaciones de abandono o desaparición del marido. En este sentido, la testigo Francisca Molana respondía que había contraído matrimonio con Pedro Kranghis, pero que este se hallaba ausente de la isla. Otra de las testigos, Práxedes Prats, declaraba que estaba casada con Jaime Castañer, de ejercicio marinero y dedicado al corso ${ }^{18}$. En ausencia del mismo había frecuentado la amistad de un coronel inglés hasta el extremo de provocar que su marido se separara de ella, debido a la deshonra sufrida públicamente. Enterado de los pormenores de la traición Jaime Castañer decidió a su vuelta, de la que ya hacía un año, abandonar el domicilio conyu-

18. El corso se había convertido en un negocio muy lucrativo del que vivía Menorca, y constituía un fenómeno de emigración transitoria de los isleños, particularmente de los mahoneses. RIUDAVETS Y TUDURI, Pedro: Historia de la Isla de Menorca, Mahón, 1885-1887; PONS VILA, Juana Francis: «Contribución al estudio del corsarismo menorquín en el Setecientos. El viaje del jabeque «San Antonio de Pádua» a las órdenes del capitán Francesc Maspoch (1780)», Mayurqa, 21, Palma de Mallorca, 1985, pp. 233-247. 
gal e irse a vivir con sus padres. Según las últimas noticias, poco después se reincorporó al corso y fue hecho prisionero en Barcelona, donde imaginaba que subsistía por esas fechas.

La detenida Margarita Gutiérrez «Patrona», casada con Sebastián Feliu reconocía que no sabía con seguridad donde se hallaba su marido, pues hacía dos años y medio había partido para la plaza de Gibraltar, aunque le habían comentado que siete meses atrás se hallaba en Liorna con intención de dedicarse al comercio de mercancías y al corso, sin precisarle ningún detalle más sobre su situación.

Parece ser, según recoge en su obra Jorge Armstrong, gobernador de la isla en 1738, que en Menorca se conservaba una curiosa tradición que concernía a los matrimonios en los que el marido debía ausentarse por motivos de trabajo durante largo tiempo. Estos pactaban con los amigos o sus propias mujeres una señal de aviso de su retorno, para que ellas prepararan su recibimiento y también para «evitar por este medio las consecuencias funestas que resultan algunas veces de una vuelta imprevista». Debían por lo tanto suceder de forma muy frecuente los casos de infidelidad y de matrimonios rotos por esta causa, así como el nacimiento de niños con rasgos contrarios a los menorquines, es decir, de tez clara, pelo rubio y ojos azules ${ }^{19}$.

- En quinto lugar, la profesión:

Por su condición de mujeres solas, todas ellas debían buscar el modo de obtener unas ganancias económicas mínimas para sufragar los obligados gastos de su manutención y el alquiler de sus casas. En este aspecto, las profesiones que declaraban las situaba en los sectores más desfavorecidos de la sociedad. En el mejor de los casos atendían a las labores domésticas como criadas en casas de oficiales ingleses, o servían de amas de comida y limpieza reclamadas ocasionalmente por los militares ingleses que formaban parte de un importante contingente de población transeúnte destinada en Menorca. Así, Mariana Rechard relataba que había sido criada de un sargento inglés apellidado Jainer, durante un año y medio, y que éste residía en el castillo de San Felipe desde hacía tres años con su familia, compuesta de mujer y tres hijos menores. Clara Roig, madre de la anterior, que desde hacía 14 años era viuda, mantenía su casa con las ganancias que le reportaba la costura y el lavado de ropa de los ingleses, y concretamente se había hecho cargo de esos menesteres para los sargentos y cabos pertenecientes a las cuatro compañías de los Regimientos $n^{\circ} 51$ y Buff ${ }^{20}$. Sin embargo, desde la retirada de los militares al fuerte se había quedado sin trabajo. Juana María Corrones, alias «La Flamenca», negaba tener alguna relación con los ingleses, pues su economía doméstica se sostenía mediante el sueldo que ganaba con el lavado de ropa, la costura y las comidas y cenas que servía a un portugués llamado Salvador Silva. El producto

19. Armstrong, Jorge: Historia Civil, y Natural..., Op. Cit, pp. 230-231.

20. The Buff hacía referencia al nombre del color del tejido antelado utilizado para el uniforme. TERRON Ponce, José Luis: El Faro de Alejandría (II), Artículos publicados en la prensa menorquina (20072010), Menorca, 2010, p. 93. 
de estas tareas se complementaba con el hilado de telas que aportaba su madre, para entre ambas sostener a la hija huérfana de su primo. Con anterioridad a la llegada del ejército español, también se había encargado por espacio de 17 meses del cuidado de la ropa del comerciante hebreo Jacob Latis, hasta la deportación de los judíos ordenada por el duque de Crillón el 27 de agosto de 1781.

Sin embargo, a lo largo del siglo XVIII, entre estas mujeres se produjeron situaciones más comprometidas respecto a su modo de vida ${ }^{21}$, que las condujeron a distintas formas de prostitución, facilitadas por la mayor relajación en las costumbres que propiciaba el gobierno inglés ${ }^{22}$.

En ocasiones se producía una suerte de amancebamiento, ya que la naturaleza de los compromisos suponía cierta estabilidad en el tiempo y la convivencia con un hombre bajo el mismo techo. De esa manera, una mujer podía haber mantenido parejas sucesivas que entrañaban cierta fidelidad, en un acuerdo de pareja distante de los meros servicios sexuales prestados a cambio de una cantidad pactada. Este tipo de relaciones suponían el beneficio de la compañía mutua, al menos según querían interpretarlo las interesadas. Así eran las aparentes circunstancias de Margarita Gutiérrez, alias «Patrona», según ella misma reconocía, pues después de la desaparición de su marido se ganó la vida durante un año con el trabajo de sus manos: «bordar, coser y las demás labores de mujeres», hasta que entabló relaciones, primero de amistad y más tarde amorosas, con un sargento inglés llamado Juan Flud. Una de sus amigas aseguraba que Margarita había hecho «vida de enamorada en el Castillo». Este sargento la había mantenido hasta la llegada de la escuadra española. A partir de entonces, cuando el sargento se retiró al castillo de San Felipe, se pudo sustentar con lo que había ahorrado en la época de su relación con el inglés y con su propio trabajo.

En otros casos varias de estas mujeres aludían de manera velada o reconocían abiertamente su ejercicio en la prostitución. Margarita Anglada, alias «Pegui», de 28 años y la única de ellas nacida en Ciudadela, respondía así a la pregunta sobre su clase de vida alejada de su familia: «que se había mantenido de lo que le había producido el trato ilícito con las personas que más le agradaban». Respecto a si entre los elegidos existía algún inglés, aseguraba que especialmente con un sargento apellidado Fragilton y un cabo de nombre Will Anano, y que ambos se encontraban en aquellas fechas en la fortaleza de San Felipe junto al resto de los compatriotas que se resistían a la entrega de la isla. Además, para corroborar su actividad laboral, señalaba que tenía como vecina a una mujer inglesa, aunque de religión católica, llamada Ana Cooper, que como ella también ejercía el mismo oficio.

21. Las transgresiones a la moralidad de la época también se documentaron en los primeros años de la ocupación. Perlasia, Josep María, y PONS AlzinA, Joan: «Dones escandaloses i ordre social a Menorca (1726-1736), Manuscrits, nº 10, enero 1992, pp. 441-469.

22. El tono del gobernador de Menorca, como en el resto de su obra, revela su actitud de superioridad frente a los isleños, al tiempo que califica despectivamente a las mujeres que lo ejercen: «A la verdad tienen una viveza que las inclina frecuentemente a mantener un comercio ilícito con los Oficiales ingleses». Vid., Armstrong, Jorge: Historia Civil y Natural..., Op. Cit., p. 237. 
La mayoría de los testimonios de las mujeres detenidas por sospecha de traición, y de las testigos reclamadas para la averiguación de ese delito, confirmaban que la prostitución se localizaba en la misma zona de la ciudad de Mahón. Además, algunas compartían la misma vivienda, como Ana Anglés «La Ferranda» y Eulalia Pola, con motivo de la escasez de casas, y por haber sido desalojada la primera de la que hasta entonces habitaba. En esta ocasión, como en otras parecidas entre las detenidas, los lazos de amistad y los intereses profesionales compartían el mismo techo. Ana Anglés, aunque después de la muerte de su madre comenzó a ganarse la vida de criada en el domicilio de un inglés, a partir de independizarse de la casa de su padre se dedicó a cultivar la amistad de varios hombres, especialmente de un mahonés con el que se mantuvo hasta que éste contrajo matrimonio. Una vez fallecido su padre, había tratado «con la mayor intimidad y con comercio ilícito a un sargento inglés llamado Chuter», destinado en la guarnición británica de Menorca y perteneciente al Regimiento Buff. Respecto a la anterior, su amiga Eulalia Pola declaraba que era del mismo modo de vida que ella, aunque también ambas compaginaban la prostitución con la costura por encargo de varios hombres que las visitaban y trataban. Por su parte, Eulalia Pola reconocía que había tenido durante 6 años «la más íntima amistad con un marinero inglés llamado Jaime Silvester», que poco después se embarcó en una fragata que fue apresada por los franceses, por cuyo motivo estuvo 15 meses prisionero en ese país. No obstante, una vez recobrada la libertad regresó a Menorca y partió de nuevo con destino a Gibraltar, de donde no había regresado. Las últimas noticias que tenía sobre Silvester le situaban en Londres, desde donde escribió a Eulalia Pola para comunicarle que no tenía intención de volver a la isla.

Por último, Francisca Ortegas, alias «La Castellana», la más joven de las arrestadas, pues decía tener más de 16 años, había estado sirviendo cerca de 9 meses como criada en casa de D. Antonio Castelar, en Mahón, y desde hacía 4 meses había decidido abandonar la casa de su madre para vivir «sola y libre». Cuando tomó esa determinación ya tenía contraída amistad con Mr. Corne, un oficial de la Marina inglesa que la solicitaba. Sin embargo, sólo conservó esa relación por espacio de un mes, durante el cual la estuvo manteniendo, y a causa del acuartelamiento de los militares en el castillo de San Felipe se vio obligada a «abandonarse al trato de otros».

Pero no sólo las detenidas por sospechosas confesaban sus relaciones con los ingleses. La testigo Práxedes Prast relataba sus amistades íntimas con un coronel llamado Pringle ${ }^{23}$, con el teniente de fragata Hay y con un teniente al servicio de un barco del corso apellidado Strotem.

En general, cuando el tipo de vinculaciones eran de índole sentimental estaban condenadas tarde o temprano al fracaso, pues con hombres que pertenecían al ámbito castrense era difícil soslayar los constantes cambios de destino a los que estaban suje-

23. Se trataba del coronel que estaba al mando del Regimiento $n^{\circ} 51$, y que junto al $n^{\circ} 61$ y los hannoverianos Prinz Ernest y Goldacker (formados por mercenarios alemanes de religión católica) componían las fuerzas británicas que se enfrentaron al asedio de las tropas españolas en Menorca. TERRON PONCE, J. L.: Ejército y política en la España de Carlos III, Vol. 37, Madrid, 1997, pp. 197 y ss. 
tos; por el contrario, cuando las contraprestaciones eran sólo económicas, no estaban condicionadas a la fidelidad, pero tampoco ofrecían la seguridad de sustento regular que buscaban muchas de estas mujeres. Era lógico suponer que en el momento de la reconquista de la isla cualquier nexo entre las menorquinas y los ingleses se truncara de manera que estas volverían a encontrarse solas y desasistidas.

Las aseveraciones morales, los consejos y las confesiones de arrepentimiento respecto a esta forma de vida se expusieron en las declaraciones tomadas por San Martín y Navaz, el auditor general del ejército encargado de la averiguación de la presunta traición cometida por las detenidas, tanto por las protagonistas del supuesto delito como por las mujeres que informaron de los hechos en calidad de testigos.

Clara Roig, viuda de Rechard de 40 años, conocía desde su niñez a Francisca Ortegas «La Castellana» y dejó de tratarla por haber oído decir que «se había dado al vicio de beber» y temía que su hija Mariana Rechard tomara su mal ejemplo. Además añadía que insistía en corregir a ésta, sobre todo por el hecho de haberse ido a vivir fuera de su casa y desobedecerle en todo, anulando así la posibilidad de vigilarla. La madre trataba de imponer su lazo protector y salvaguardar la honra de su hija, aunque su falta de recursos económicos y morales hacía fracasar la autoridad que le concedía su edad y su grado de parentesco.

La vida deshonesta que reconocía Margarita Anglada, alias «Pegui», la justificaba por «su poca reflexión, de salir de casa de sus padres para vivir en libertad». También Francisca Ortegas «La Castellana» hacía referencia a su familia cuando recapacitaba acerca de su comportamiento, por un lado culpabilizándoles del rigor con que había sido educada por su madre: «por el castigo y correcciones que ésta la daba», calificado por ella de maltrato; y por otro, debido al ambiente donde se había movido: «el consejo de las malas compañías que la persuadieron a este desacierto», especialmente una mujer llamada María «La Castellana», ya difunta, de quien probablemente heredó el sobrenombre en el oficio.

También Ana Anglés «La Ferranda» responsabilizaba de su torcido destino a una amiga de cuyo ejemplo «adquirió el vicio de la libertad, y por querer disfrutar de ella se separó enteramente de su padre», confundiendo el significado del término libertad, pues en el resto de su declaración también calificaba su vida como «libertina», según se asociaban ambas palabras en los parámetros morales más usuales del Antiguo Régimen.

Respecto a lo que declaraban las testigos Maria Morla, alias «Pincha» y Francisca Molana, la primera destacaba que todas las mujeres nombradas en el expediente tenían amistad íntima con varios de los ingleses (sargentos, soldados y cabos), que entonces se encontraban atrincherados en el fuerte de San Felipe; la segunda, que exceptuaba a Clara Roig, tildaba al resto como «mujeres de mala vida», y añadía más nombres a la lista de las sospechosas por su trato con los ingleses, como el de Margarita, 
alias «Chueta» ${ }^{24}$, «por ser una que ha servido mucho, y actualmente sirve de Tercera a muchas de las que viven con deshonestidad $\rangle^{25}$.

Para evaluar la calidad moral de las detenidas también se incluyó en el interrogatorio una pregunta respecto a sus antecedentes penales, aunque ésta no se planteó a todas las mujeres. Algunas declaraban no haber sido nunca procesadas ni detenidas por no haber dado motivo para ello, como así lo afirmaban Mariana Rechard, Francisca Ortegas «La Castellana» y Práxedes Prats. Sin embargo, otras habían sido protagonistas de algunos incidentes menores que supusieron su temporal encarcelamiento.

Juana María Corrones, alias «Flamenca», había sido encarcelada dos veces: la primera sucedió 10 años atrás por haber comprado una camisa a un soldado; sin embargo, al día siguiente del arresto fue puesta en libertad a cambio de pagar una multa de 10 pesos; de la segunda ocasión hacía 6 años, causada por una riña entre otras dos mujeres, una de las cuales había proferido injurias sobre la otra resultando inculpada ella, si bien al tercer día se la declaró inocente y fue puesta en libertad.

Margarita Gutiérrez, alias «Patrona», fue arrestada junto a otro vecino de Mahón con quien mantenía una relación ilícita, pues además era casado, y cuya mujer los denunció. Este delito lo había cometido hacía 4 años y aunque no fue procesada la mantuvieron en prisión 24 horas, y salió libre sin costas.

Eulalia Pola fue conducida a la cárcel pública por la queja de unos vecinos motivada por el escándalo que ocasionó en su casa otra mujer que estaba borracha. Como consecuencia de ello permaneció en la prisión por 3 días, pero el incidente había sucedido hacía 5 años, y tampoco fue procesada ni le impusieron multa alguna.

Finalmente, en la misma época Clara Roig fue detenida dos días, al cabo de los cuales la pusieron en libertad a causa de una acusación infundada. Ella había sido víctima del robo de un cerdo de su propiedad, y los ladrones dejaron abandonada en su casa una falda de niña. Al no encontrar al dueño de la prenda decidió que la usara su hija, momento en el que apareció el mismo, que la denunció.

\section{EL CONTACTO CON LOS INGLESES DEL CASTILLO DE SAN FELIPE}

Además de tener en cuenta las facetas más relevantes de la vida de estas mujeres, su situación familiar, estado civil, profesión, sus amistades y el historial delictivo era preciso conocer quiénes de ellas seguían en contacto con los militares ingleses del castillo de San Felipe, y por lo tanto eran sospechosas de traición a la Corona ${ }^{26}$, pues cualquier información que filtraran respecto a las tropas españolas podía hacer fracasar

24. Francisca Molana ignora su apellido y solo sabe el apodo que le acompaña. Chuetas es un término peyorativo que denomina a los judíos conversos instalados en Mallorca y característica del antisemitismo español. JOAN TOUS, Pere: «Los Chuetas de Mallorca: Textos persecutorios, negociación del estigma y reivindicación literaria», El antisemitismo en España, Universidad de Castilla La Mancha, 2007, pp. 127-164.

25. Es decir, servir de alcahueta.

26. El mismo día 19 de agosto en que se tomó la isla de Menorca, el duque de Crillón emitió un bando que relevaba a los menorquines de su fidelidad a la Corona inglesa y les ordenaba que realizaran un juramen- 
la planeada y rápida reconquista del fuerte, y la consecuente salida de los enemigos de la isla de Menorca. Esta presunción podría ser verosímil teniendo en cuenta los lazos sentimentales, de complicidad, dependencia, agradecimiento y simpatía que existían entre estas mujeres de Mahón y los militares británicos.

Preguntadas las mujeres sobre si conocían los motivos de su prisión la mayoría contestaba negativamente. Aunque de forma velada, parecía que las amigas Eulalia Pola y Ana Anglés «La Ferranda» imaginaban la causa, pues en el momento de prenderlas se oyó decir a la primera en menorquín: «bien te decía yo, y me lo temía hace algunos días, que esto nos había de suceder», comentario que justificaron por la amistad que tenían con un criado de un señor español con el que mantuvieron relación ambas al mismo tiempo, incidente por el que pudieron ser denunciadas y, según ellas, en lugar de castigar al hombre penalizarlas a ellas. Sólo Margarita Gutiérrez, alias «Patrona» respondió con seguridad respecto a admitir el origen de su detención. Ésta suponía que la causa podía deberse al hecho de que en el registro de su casa se encontraran algunos efectos que pertenecían a los ingleses. Desde el instante de su arresto se había anticipado a decir que no hallarían nada, salvo dos paquetes de cartuchos con bala que descubrió abandonados en una ventana de los cuarteles ingleses del arrabal nuevo, cinco días después de la llegada del ejército español, y que creyó que contenían dinero, así como medio cerco de hoja de lata que necesitaba para protección de su chimenea. Así que imaginó que ese sería su delito pues era consciente del bando publicado por el capitán general duque de Crillón que prohibía a los menorquines guardar bienes de los enemigos.

No sería la única a la que se le podía acusar de tener objetos de los ingleses, pues dada la dedicación a la costura y lavado de prendas, al servicio de comidas y al alojamiento ocasional de algunos militares era lógico que algunas pertenencias fueran olvidadas en sus casas, debido a la rápida y sorprendente llegada de las tropas españolas. También Clara Roig reconocía guardar varias prendas del sargento Jainer ${ }^{27}$, a título de favor personal hacia el militar, que le solicitó su recaudo para el caso de que regresara algún día del castillo de San Felipe. En caso contrario, el sargento se las regalaría como pago de los servicios recibidos de Clara Roig, circunstancia que también aprovecharon otros ingleses que le adeudaban algunos trabajos y que depositaron otras ropas en dos arquillas de su casa.

El interés de las nuevas autoridades se dirigía sobre todo a obtener algún tipo de información que pudiera conducirles a resolver el asedio al castillo con la mayor diligencia posible. Sin embargo, no era menos vital evitar que se filtraran las intenciones

to de fidelidad al Rey de España. A.G.S., Guerra Moderna, Leg. 3.768: Bando del duque de Crillón, 19 de agosto de 1781.

27. El registro de efectos dio como resultado el hallazgo de cuatro casacas de uniforme, varias camisas, chupas, calzones, zapatos, medias, sombreros, entre otras prendas. A.G.S., Secretaría de Despacho de Guerra, Leg. 7.312: «Expedición de Menorca. Traiciones», Expediente n ${ }^{\circ} 48$ : «Diligencia y reconocimiento, 6 de noviembre de $1781 »$. 
y la táctica que preparaba el ejército español para tal efecto, y en consecuencia anular cualquier tipo de comunicación de los mahoneses con los enemigos.

Según las noticias manifestadas por el duque de Crillón y que justificaban el arresto y castigo de estas mujeres, existían dos cuestiones que las podían incriminar: en primer lugar, la sospecha de que alguna de ellas se había acercado y quizás introducido en el castillo de San Felipe aprovechando un disfraz de hombre; y en segundo lugar, la correspondencia que se intercambiaba entre la fortaleza y las gentes de Mahón, y que fueron las transgresiones que con mayor insistencia se trataron de averiguar en el tribunal de guerra habilitado por el auditor general del ejército San Martín y Navaz. Las pesquisas y el interrogatorio respecto a la primera cuestión dieron como resultado el siguiente relato:

María Morla, alias «Pincha», antes de la salida de los ingleses de Mahón, descubrió en una ocasión a su entonces amiga Francisca Ortegas «La Castellana» disfrazada de hombre, según le contó, para acudir junto a un criado a una cena en casa de un general. Entonces se le ocurrió aprovechar la situación para solucionar sus problemas amorosos con José Fasa (con quien tenía promesa de matrimonio), y pedirle a «La Castellana» que fuera junto a ella con esa vestimenta hasta el Hospital del Convento de San Francisco, donde trabajaba aquél, para hacer creer a su prometido que la acompañaba otro hombre y así provocar sus celos. Por su parte, «La Castellana», aunque sólo recordaba en un principio haberse disfrazado con atuendos masculinos en las Carnestolendas, al finalizar el interrogatorio recordó que María Morla «Pincha» la obligó una vez a acompañarla simulando ser un hombre para provocar al novio de aquélla, suceso que había olvidado por haberse peleado con ella. Las prendas se las había proporcionado otra mujer (Juana María alias «Benilloba»), pues guardaba en su casa ropa de un marinero, que con anterioridad le había prestado para las fiestas del Carnaval. El contenido de ambas declaraciones fue modificado sustancialmente por la testigo Francisca Molana, al asegurar que María Morla «Pincha» había acudido al castillo de San Felipe en traje de hombre, aunque no sabía cuántas veces había sucedido esto, pero sí que había acontecido después de la llegada del ejército español a Mahón.

Entre el resto de las mujeres alguna declaraba el uso del traje de hombre, como Juana María Corrones, alias «Flamenca», por ser una costumbre popular en la isla durante las Carnestolendas; la mayoría desconocía que alguna de las arrestadas utilizara o tuviera dicho disfraz.

En realidad la posibilidad que ofrecía tal vestimenta para simular otra identidad suponía salvaguardar a quien la usara de las posibles consecuencias infractoras de su uso; sin embargo, la gravedad del hecho se encontraba en la facilidad que, por lo visto, existía para acercarse a las inmediaciones de la fortaleza e incluso para introducirse en la misma, sorteando sin problema la obligada vigilancia militar a que estaría sujeto el castillo y cualquier movimiento del enemigo, cuestión que inducía a pensar en la complicidad de terceras personas.

Al parecer la comunicación entre San Felipe y Mahón era sobradamente conocida y ejercida, en ocasiones, por las mujeres del entorno que se describe. A través del testimonio aportado por Ana Anglés, alias «La Ferranda», se podía comprobar cómo la 
circulación de recados era constante e incluso un motivo de rivalidad entre las agraciadas que los recibían, tal y como le había confiado María Ferrer, alias «Peu Descals», que vivía en compañía de la testigo María Morla, alias «Pincha». María Ferrer presumía del recibo de varios mensajes enviados por Jaime Klark, un músico inglés que se recogió en San Felipe, y que enviaba «muchas memorias desde el Castillo». Además este extremo fue ratificado por un cabo del Regimiento de Voluntarios de Cataluña, conocido como «Garganta», que se encontraba acampado muy cerca del castillo («A tiro de piedra») y que de su conversación con Klark recordaba lo siguiente:

«que si podía desertar del castillo, antes de que se hiciese fuego a él por los españoles, lo ejecutaría viniendo a servir en calidad de músico en la tropa de España, pero que si no lo podía conseguir y empezaba antes el fuego tendría paciencia,...»

Las condiciones de vida en el castillo de San Felipe fueron empeorando hasta extremos insoportables, sobre todo por la deficiente alimentación que provocó numerosas muertes a causa del escorbuto. En consecuencia los intentos de deserción fueron habituales, y algunos culminaron con éxito. La declaración de esas intenciones por parte del músico significaba una confirmación sobre el deplorable estado de ánimo de los recluidos ${ }^{28}$.

En principio el control de la correspondencia no debía suponer un problema para las autoridades españolas en la isla, pues era confiscada y leída por orden del duque de Crillón, para evaluar su riesgo, y una vez comprobado su contenido era entregada a sus destinatarios. El peligro residía en aquellos canales de comunicación ideados por los enemigos con la complicidad de algunos mahoneses y que escapaban de la inspección gubernativa. Por este motivo se trató de investigar los movimientos de las mujeres por la isla y los lugares y personas que frecuentaban.

El interrogatorio contemplaba una serie de preguntas relativas a las costumbres que mantenían estas mujeres cuando disponían de tiempo libre o era festivo. Así, eran frecuentes los paseos fuera de Mahón por las huertas y viñas más cercanas, habitualmente para comprar verduras y frutas. También solían acercarse al Nuevo Arrabal, tanto por el camino de tierra como por la Marina en bote, e incluso a calas cercanas, como la de Alcaufar donde acudió Mariana Rechard invitada a comer por el capitán de un jabeque a quien cuidaba la ropa. Otro entretenimiento consistía en visitarse mutuamente en sus casas y beber aguardiente. Mariana Rechard recordaba haberse acercado a las inmediaciones de la fortaleza para ver a un ajusticiado que habían ahorcado en aquel lugar. Sólo Eulalia Pola confesaba su estancia en el castillo de San Felipe, el mismo día de la llegada de las fuerzas de Crillón, el domingo 19 de agosto, entre las 2 y las 5 de la tarde, con la intención de acompañar a su amiga Ana Anglés, alias «La Ferranda» a que viera al sargento Chuter. Sin embargo, Ana Anglés había declarado que un mes antes de la toma de la isla por los españoles ya había reñido con el sargento,

28. Para una fiel descripción de las circunstancias que se vivían en el Castillo, Vid., LoPe, Hans Joachim: «Christoph F. H. Lindemann: Un testigo alemán de la reconquista de Menorca en 1782», en Anuario de Estudios Filológicos, vol. XXX, Universidad de Extremadura, 2007, pp. 179-183. 
a causa de no querer pasar la noche en su compañía dentro del castillo, ocasión en que el sargento Chuter le pegó y ella dio queja del maltrato recibido a su coronel.

La máxima preocupación seguía siendo la de descubrir a las personas que recibieron misivas del castillo de manera furtiva una vez instalado el nuevo mando en la isla, según las noticias difundidas. Las averiguaciones en este sentido aportaron informaciones sólo anecdóticas y que estaban más relacionadas con asuntos del corazón que de la política. La mayoría aseguraba que no había enviado ni recibido cartas del fuerte de San Felipe, y tampoco conocían que otras mujeres lo hubieran hecho. Esta última afirmación era fácilmente comprobable pues todas las detenidas e incluso las testigos eran analfabetas, de manera que necesitaban la ayuda de terceros para saber el contenido de cualquier correspondencia. Por lo tanto la confidencialidad de los mensajes era imposible, ya que normalmente la interesada acudía acompañada a alguna casa donde se leía las respectivas cartas.

Sólo dos de las mujeres protagonizaron sendas habladurías que habían sido comentadas en su ambiente por las protagonistas y algunos testigos. En primer lugar, Ana Anglés, alias «Ferranda» fue señalada por haber acudido a casa de un mahonés de oficio albañil, llamado con el sobrenombre de «Rotos», por indicación de Nely Ashely, una mujer inglesa que fue expulsada del castillo acusada de ladrona. Esta última le dijo que en casa del albañil tenía una carta del sargento Chuter, con una guinea que en realidad resultó estar dirigida al padre del mismo, tambor mayor del regimiento Buff que se hallaba prisionero en Fornells. Este asunto era público, pues fue ratificado por la testigo Maria Morla «Pincha», Eulalia Pola y la propia Ana Anglés, además de que la carta había sido interceptada por orden del duque de Crillón y llegaba abierta como el resto de la correspondencia que salía de San Felipe y podían requisar. En segundo lugar, Margarita Gutiérrez, alias «Patrona», confesó que, aunque no tenía trato con el sargento Flud, hacia 5 semanas había fingido recibir una carta suya para molestar a Rafaela Vinent, alias «Monja», antigua compañera de casa con quien estaba reñida. Esta última difundió el rumor de que le había comunicado a Flud que Margarita estaba en tratos con los españoles. La afectada replicó con ironía que en una carta el sargento le había dado su permiso:

«que estaba muy gustoso y contento con que admitiese el trato de los españoles pues si con él, que era protestante había sido mala, estaba más gustoso de que lo fuese con los católicos».

Para convencer a su enemiga se valió de una carta prestada que mostró con la seguridad de que Rafaela Vinent no sabía leer. Así pues, no pudo demostrarse que este grupo de mujeres actuaran de espías conscientes o inconscientes, pues fueron víctimas de las circunstancias que las señalaban en momentos tan delicados, como peligrosas e inconvenientes, probablemente por su modo de vida y por sus compañías.

Finalmente, según constaba por las diligencias practicadas hasta la fecha sobre las posibles faltas cometidas por estas diez mujeres, se llegó a la conclusión de que no existía delito, y mediante un auto fechado en Mahón el 8 de noviembre de 1781, se 
sobreseyó el caso ${ }^{29}$. A partir de entonces las mujeres podían quedar en libertad mediante la presentación de fianzas. Las condiciones de la prisión debieron ser muy duras pues el 22 de noviembre acudió un médico a la cárcel pública a causa de la enfermedad de carácter ginecológico que aquejaba a Juana Maria Corrones «Flamenca». Según el diagnóstico del doctor, el intenso frio y el hacinamiento de las mujeres impedía su mejoría, a pesar de los medicamentos que le había suministrado, y por lo tanto aconsejaba su puesta en libertad pues de otro modo el mal que la aquejaba sería incurable ${ }^{30}$.

Este trámite de la excarcelación fue lento, pues no consiguieron la salida de prisión hasta el día 10 de diciembre. Eulalia y Catalina Pola consiguieron que su hermano Manuel Pol acudiera como fiador; por parte de Clara Roig y Mariana Rechard lo hizo Jaime LLufriu; Antonio Boero Izquierdo se prestó en representación de Ana Anglés «La Ferranda», Francisca Ortegas «La Castellana» y Margarita Anglada «Pegui»; Francisco Spineta por Juana María Corrones «Flamenca»; y Pedro Gutiérrez por Catalina Morro. Sin embargo en el expediente no aparece ni el fiador ni la puesta en libertad de Margarita Gutiérrez, alias «Patrona» ${ }^{31}$.

\section{UN NOVIAZGO INTERRUMPIDO}

Otro asunto de semejante naturaleza, y enmarcado en las pesquisas respecto a la inconveniente comunicación entre los menorquines y los ingleses del castillo de San Felipe aparecía en un segundo expediente cursado en fechas cercanas ${ }^{32}$. En esta ocasión se trataba del arresto domiciliario, «con guardia y centinelas de vista» ante la carencia de espacio en la cárcel pública, de la familia de Antonio Arnau, compuesta por Isabel Seguí, su mujer, y Juana Arnau y Seguí, su hija; así como parte de su futura familia política, integrada por Magdalena Pons, viuda de Marcos Reurer, Águeda Reurer Pons, su hija, y Antonio Pons Alcina, marido de esta última.

De nuevo el auditor general del ejército, Juan Bautista de San Martín y Navaz fue el encargado de las diligencias convenientes para la averiguación del tipo de relaciones establecidas entre esta familia y los enemigos. El 11 de noviembre de 1781 se procedió a tomar declaración a los detenidos sobre el contenido de la correspondencia remitida desde el castillo de San Felipe, que se había interceptado por parte del duque de Crillón, y dirigida a algunos de los miembros de esa familia. El expediente venía precedido por una carta fechada el 17 de septiembre de 1781 y remitida a Juana Arnau por Marcos Reurer.

29. A.G.S., Secretaría de Despacho de Guerra, Leg. 7.312: «Expedición de Menorca. Traiciones», Expediente $\mathrm{n}^{\mathrm{o}}$ 48: Auto, 8 de noviembre de 1781.

30. A.G.S., Secretaría de Despacho de Guerra, Leg. 7.312: «Expedición de Menorca. Traiciones», Expediente n ${ }^{\circ}$ 48: Certificado de D. Antonio Pons, 26 de noviembre de 1781.

31. A.G.S., Secretaría de Despacho de Guerra, Leg. 7.312: «Expedición de Menorca. Traiciones», Expediente $\mathrm{n}^{\circ}$ 48: Auto, 10 de diciembre de 1781.

32. A.G.S., Secretaría de Despacho de Guerra, Leg. 7.312: «Expedición de Menorca. Traiciones», Expediente $n^{\circ} 51$. 
Junto a la orden de registro del domicilio y la requisa de papeles de importancia que hubiese en el mismo, se procedió a la toma de declaraciones. El primer interrogado fue el cabeza de familia, Antonio Arnau, de 52 años, natural y vecino de Mahón, casado y padre de tres hijas (Antonia, Elisabeth y Juana), de ejercicio navegante, que años atrás había tenido mando en varias embarcaciones, aunque trabajaba desde el mes de junio en el puerto, como guarda de un barco a las órdenes de un inglés llamado Mr. Simpson. Sobre su arresto, incomunicado del resto de su familia, manifestó desconocer la causa, pues en su opinión no había dado motivos, aunque le informaron que una vez le fuera tomada su declaración se le dejaría libre para regresar a su trabajo.

Preguntado sobre las personas que en el período de un año acostumbraban a visitar su casa, reveló que con mayor frecuencia trataban con los vecinos, cuatro familias que tuvieron que abandonar el Arrabal Nuevo donde vivían, por huir del riesgo del asedio al castillo de San Felipe, pues las tropas españolas habían acampado en las inmediaciones del mismo. También era habitual la visita del maestro de música José Sany, encargado de enseñar a tocar el bandolín y solfeo a sus hijas Juana y Elisabeth; y a diario un sobrino llamado José Amat Seguí. Además, desde hacía un año acostumbraban a visitarles el capitán Don, secretario del gobernador inglés, y un capitán de infantería llamado Marcos Reurer Pons. Este último, aunque nacido en Menorca, se encontraba empleado en el castillo desde hacía 4 ó 5 años. Ambos suspendieron su asistencia a ese domicilio a partir de la llegada de las fuerza españolas y con motivo de la retirada de los ingleses al fuerte de San Felipe, donde permanecían en esos días. Sin embargo, el contacto con ellos había continuado a pesar de las adversas circunstancias. La noticia de esta evidencia era conocida por las autoridades españolas pues las cartas eran interceptadas por el duque de Crillón, que posteriormente las remitía a los interesados de manos de su secretario D. Miguel Arnau, una vez abiertas y leídas, y a través del maestro de música José Sany.

Por un lado, Antonio Arnau justificaba la correspondencia entre su hija Juana y Marcos Reurer por el compromiso de matrimonio que habían adquirido con anterioridad a la reconquista de Menorca, de manera que las cartas eran de contenido amoroso. Por otro, la mujer del declarante, Isabel Seguí, recibió una misiva del secretario del gobernador inglés, capitán Don. El motivo de esta relación se explicaba por la amistad que habían entablado desde que se ofició un año atrás la boda de su hija Antonia con Samuel Bish, un católico nacido en Mahón, pero de origen irlandés. Tras la ceremonia del enlace se había celebrado un baile en el domicilio del novio, donde concurrió el mencionado capitán convidado por el contrayente y así conoció a su familia.

La declaración de Isabel Seguí, de más de 50 años, natural y vecina de Mahón, y mujer de Antonio Arnau, sólo añadía a lo relatado por su marido que el trato con el capitán Don había sido «una amistad regular y política por venir de visita a su casa». El contenido de las cartas, tanto del capitán Don como del prometido de su hija, se limitaban a los saludos habituales y a confirmar que gozaban un buen estado de salud. Las respuestas a las mismas habían sido remitidas por el mismo conducto, es decir, a través del maestro de música, que también escribió de parte de Isabel Seguí, pues esta 
no sabía, y nuevamente dirigidas a la casa del Duque de Crillón, antes de su esperada entrega en el castillo.

En cuanto a Juana Arnau y Seguí, hija de los anteriores, nacida en Mahón y de 17 años de edad, respondía en su declaración que había dispuesto una respuesta a la primera carta de su prometido, pero que antes de enviarla recibió una segunda, de manera que cambió la fecha (13 de septiembre) y le encargó a José Sany que la remitiese a la casa del duque de Crillón abierta, tal y como le llegaban a ella.

Las cartas, entregadas al auditor general del ejército, se añadieron al expediente, y su contenido era el declarado por las afectadas. El recado dirigido, equívocamente, a Isabel Seguí era como sigue:

«Fort. Sh. Philips 29 Augt 1781

Carisima Señora,

Li desitx la major felicidad y esper tenir prest el quesi inexpressible de poderla veure. G.D.

A Señora Elizabetta Arnau»

A pesar del escueto contenido era evidente que la destinataria no era la mujer de Antonio Arnau, es decir, Isabel Seguí, sino la hija de ambos y que aparece en todos los escritos con distintas variaciones del nombre de Elisabeth y no de Isabel.

Las enviadas a Juana Arnau y Seguí por Marcos Reurer, fechadas el 29 de agosto, el 1 y el 13 de septiembre, eran muy parecidas entre sí. Reflejaban las típicas declaraciones de amor, la preocupación por encontrarse separados y por el estado de salud de toda la familia, sin hacer ninguna mención a la situación que se padecía dentro del castillo, ni pregunta alguna sobre las circunstancias que se vivían en la ciudad de Mahón. Comenzaban con párrafos como:

«Carisima Estimade del Meu Cort Sra. Juana yo voldría que esta quatre malformades lletres tretas de dins el centro del meu cor li encuntrassen ab una salut perfeta com mon cor dessitja... yo li fas asebra com del dia, hora y instant, que yo ensom despertal de la seva amada presencia, no he tingut una hora de legria cumplida»

Una vez reconocidas las cartas por las interesadas se procedió al registro de una caja y una papelera que guardaban papeles antiguos, cuentas y recibos. Al día siguiente, 12 de noviembre, compareció el maestro de música José Sany para ser también interrogado. En primer lugar se apresuró a aclarar que la carta del capitán Don estaba dirigida a Elisabeth Arnau y Seguí y no a su madre, y le fue entregada junto a otra para su hermana Juana Arnau y Seguí por el secretario del duque de Crillón. Según Sany, el contexto de las cartas que leyó el propio declarante «se reducían a expresiones de cariño y a dar noticia de la salud como de quien escribe enamorado», mientras que las respuestas se limitaron a acusar el recibo y contestar lo esperado. El maestro de música también reconocía que el secretario del duque de Crillón, D. Miguel Arnau, le entregó otra carta dirigida esta vez a la madre de Marcos Reurer, y del mismo modo que las anteriores, con el contenido a la vista.

Inmediatamente se tomó declaración a Magdalena Pons, viuda de Marcos Reurer, vecina y natural de Mahón, de 50 años de edad y madre del capitán Reurer. Arrestada desde el domingo día 11 de noviembre al igual que los anteriores, afirmaba que su hijo 
se hallaba destinado en el castillo de San Felipe en calidad de teniente de la tropa de Marina, por nombramiento de su general como premio a sus servicios de ocho años en las embarcaciones de S.M. británica. Sólo había recibido una carta de su hijo, a la que no respondió por no darle ocasión de escribir nuevas cartas, tal vez con la intención de protegerle debido a la comprometida situación en que se hallaban, a pesar de que Marcos Reurer se quejaba de que todos los ingleses del fuerte recibían cartas de Mahón mientras él no.

A continuación prestó testimonio Águeda Reurer Pons, de 29 años de edad, también natural y vecina de Mahón e hija de la anterior. Casada con Antonio Pons, ambos vivían en casa de su madre, y respecto a su hermano Marcos Reurer sólo tenía las noticias incluidas en la carta que le llegó a su madre, y también confirmaba la relación amorosa que mantenían su hermano y Juana Arnau. El último de los arrestados, Antonio Pons, de 31 años de edad y de profesión cirujano, confirmaba su residencia en casa de su suegra desde hacía 5 años, así como todo lo expuesto por aquella y por su mujer.

Finalmente, todos los afectados fueron puestos en libertad, sin depositar fianzas, y sobreseído el proceso judicial que les acusaba de traición, el 12 de noviembre de 1781, al día siguiente de su arresto, al comprobar que no existían pruebas para atestiguar que se revelaran las disposiciones del ejército español a los enemigos del castillo de San Felipe, al igual que en el expediente anterior ${ }^{33}$.

A diferencia del grupo de mujeres arrestadas cuyas integrantes se encontraban asimiladas a una comunidad marginal, ninguno de los miembros de las familias Arnau y Pons tenía antecedentes penales. Además, el grado de formación de estos últimos era muy diferente, pues además de que los hombres de ambas familias ejercían profesiones reconocidas y destacaban por su nivel de alfabetización, las mujeres también empezaban a distinguirse de las de su género, pues aunque las de la primera generación, es decir, Isabel Seguí y Magdalena Pons reconocían no saber escribir ni leer ${ }^{34}$, Juana Arnau Seguí decía saber leer ${ }^{35}$, y Águeda Reurer Pons dominaba ambas habilidades.

En adelante, el auditor general del ejército, Juan Bautista de San Martín y Navaz, fue premiado por sus méritos aún sin haberse conformado la Junta de Gobierno para la isla, ya que fue nombrado por S.M. como vocal de la misma, añadiéndole para su distinción el cargo de secretario.

Juan Bautista de San Martín y Navaz, auditor general del ejército, había destacado entre sus múltiples encargos, por la prudente aplicación de la justicia en aquellos primeros días de lógica inquietud, dando muestras de diplomacia hacia la población, y reconociendo la dificultad de su ejercicio como:

33. A.G.S., Secretaría de Despacho de Guerra, Leg. 7.312: «Expedición de Menorca. Traiciones», Expediente $n^{\circ}$ 51: Auto, 12 de noviembre de 1781.

34. Según confesaba Isabel Seguí, había pedido ayuda al maestro de música José Sany para responder al capitán Don.

35. Para responder a su prometido solicitó la asistencia de su primo José Amat Seguí. 
«lo más notable y trabajoso, el tiento y el modo en que en todo ha tenido que observar...para el ánimo de estos naturales, para conservar, y no desmerecer la aceptación y aprecio de los jefes, para no disgustar a todos los demás» ${ }^{36}$

Prueba de ello era la ausencia de quejas entre los militares, los menorquines, y los extranjeros, y según el mismo hacía gala, sin faltar en nada a su obligación.

Aunque diez días después de la capitulación del castillo de San Felipe, producida el 4 de febrero de 1782, reconocía que los asuntos referidos a lo militar y a lo religioso estaban prácticamente solucionados, a su juicio faltaba el más importante y que también se hallaba bajo su competencia, como era el de establecer un gobierno político y económico. Consideraba que la función de la Junta de Gobierno que se había establecido en la isla de Menorca era muy eficaz y necesaria, mientras se acabaran de arreglar todos los asuntos pendientes tras la reconquista, pues además contaba con el respaldo popular: «porque los naturales están muy consolados y gustosos con ella ${ }^{37}$.

Pocos días después de intervenir, entre otros asuntos en la resolución de estos expedientes, el día 18 de noviembre de 1781, fue condecorado con los honores de Casa y Corte. El currículum vitae de Juan Bautista de San Martín y Navaz mostraba una carrera brillante. Sus inicios en 1763 como juez de visita de escribanos en el reino de Cádiz fueron recompensados con el nombramiento de abogado general de la Capitanía General de Castilla la Nueva en 1768. Alcanzó el empleo de auditor general del ejército el mismo año 1781, para participar en la expedición de Menorca. Finalmente, conforme a sus méritos especialmente logrados en dicha isla, fue promovido a consejero togado de Guerra de continua asistencia ${ }^{38}$.

\section{CONCLUSIONES}

Durante los cinco meses de asedio al castillo de San Felipe se fueron rompiendo los nexos que unían a la población menorquina con sus anteriores ocupantes y las esperanzas de recuperar el entendimiento con los que hasta entonces representaban el poder. Lo contrario era un delito y significaba una traición. Por lo tanto, la prostitución ejercida con los militares británicos cesó, como la posibilidad de mantener los ingresos obtenidos por sus servicios. Esta ocupación había constituido un factible remedio para salir eventualmente de la pobreza, en un ambiente como el de Mahón claramente permisivo con estas actividades, y bajo un gobierno que se caracterizaba por su tolerancia entre nacionalidades, religiones y ocupaciones económicas de toda índole. Del mismo modo, desaparecieron las labores de servicio doméstico que demandaban soldados y

36. A.G.S., Guerra Moderna, Leg. 1369: «Memorial de D. Juan Bautista de San Martín y Navaz, 15 de febrero de 1782».

37. A.G.S., Guerra Moderna, Leg. 1369: «Memorial de D. Juan Bautista de San Martín y Navaz, 15 de febrero de 1782».

38. Andújar Castillo, Francisco: Consejo y consejeros de Guerra en el siglo XVIII, Granada, 1996, p. 266. 
oficiales, y que constituyeron en unos casos una forma de ganarse la vida, y en otros un complemento necesario para la subsistencia.

La búsqueda de un hombre que les ofreciera su protección y la seguridad de unos ingresos más o menos regulares determinaron sus relaciones y la dependencia hacia los militares ingleses, a veces teñidas de rasgos sentimentales, pero en la mayoría de los casos abocadas a la transacción monetaria.

Sin embargo, también se pudo comprobar cómo existieron otro tipo de relaciones con ambición de futuro, es decir, de formalizar un matrimonio, que de igual modo fueron interrumpidas. Pero esta vez se trataba de un menorquín al servicio del ejército inglés en el mismo castillo donde resistían los enemigos. Los matrimonios entre menorquines e ingleses eran casi imposibles debido a la diferencia de religiones ${ }^{39}$, de manera que sólo las relaciones ilegítimas podrían dar su fruto con el nacimiento de niños no reconocidos.

La brusca ruptura política que supuso la sustitución de nacionalidad para la isla de Menorca trajo consigo un profundo e inmediato cambio de la vida de sus naturales, acostumbrados desde su nacimiento a la presencia inglesa. Las consecuencias de esta alteración perjudicaron en mayor medida a aquellas mujeres cuyas delicadas circunstancias eran fácilmente condenables, tanto en su vertiente moral como en la legal. Puesto que su modo de vida no se ajustaba a los parámetros de honradez de su época, sobre todo los preconizados por el catolicismo español, era lógico suponer que sus faltas morales fueran parejas a su probable deslealtad a la nueva Corona, que a partir de entonces les gobernaría y debía someterles a sus leyes. A pesar de los prejuicios, tal y como se pudo comprobar, no fueron castigadas a penas de cárcel, aunque su futuro seguiría condenado a la miseria de vender sus vidas para lograr subsistir, en una situación agravada por la disminución de la clientela y perseguida por los códigos de conducta españoles.

La ausencia de una figura masculina, obligatoria en una época en la que las mujeres dependían del permiso paterno o del esposo para cualquier gestión vital, también las colocaba en una situación de inferioridad de condiciones. Huérfanas de esa figura responsable de sus mínimos derechos, eran fáciles víctimas de atropellos y abusos. Para evitar o mitigar en lo posible ese angustioso destino se acogieron al recurso de la solidaridad entre ellas, para aliviar en grupo sus duras condiciones de vida, aunque en las ocasiones extremas, y amenazadas por una condena, en la cárcel fueran capaces de delatarse.

En definitiva, en la historia de la mujer, la falta de medios económicos, la marginalidad y la prostitución compartían el mismo nexo, del mismo modo que la pérdida del honor se asociaba a la presunción de delincuencia.

39. No obstante, en alguna ocasión sí se produjo la huida de mujeres para forzar un matrimonio con ingleses, tras la necesaria conversión al protestantismo. Perlasia, Josep María, y Pons AlzinA, Joan: «Dones escandaloses...», Op. cit., pp. 441-469. 